\title{
Dietary diversity and meal frequency among infant and young children: a community based study
}

\author{
Aysheshim Kassahun Belew ${ }^{1 *}$, Bekrie Mohammed Ali, Zegeye Abebe ${ }^{1}$ and Berihun Assefa Dachew²
}

\begin{abstract}
Background: Insufficient quantities, frequencies, and inadequate quality of complementary feedings have a negative effect on child health and growth, especially in the first two years of life. Therefore, the aim of this study was to assess the minimum dietary diversity, meal frequency and its associated factors among infants and young children aged 6-23 months at Dabat District, northwest, Ethiopia.
\end{abstract}

Methods: A community- based cross-sectional study was conducted from February 15 to March 10, 2016. The simple random sampling method was used to select study participants. An interviewer- administered structured questionnaire was used to collect data. Both Crude and Adjusted Odds Ratio with the corresponding 95\% confidence interval were calculated to show the strength of association. In the multivariable analysis, variables with less than $0.05 P$-value were considered statistically significant.

Results: The proportion of children who met the minimum dietary diversity and meal frequency were 17\% (95\% Cl: 14.9, 19.4\%) and 72.2\% (95\% CL: 69.3, 75\%), respectively. Satisfactory media exposure (AOR $=2.79 ; 95 \% \mathrm{Cl}: 1.74$, 4.47), postnatal care visits ( $A O R=1.96 ; 95 \% \mathrm{Cl}: 1.32,2.88)$, participation in child growth and monitoring follow ups $(\mathrm{AOR}=1.65 ; 95 \% \mathrm{Cl}: 1.14,2.39)$, age of children $(\mathrm{AOR}=2.34 ; 95 \% \mathrm{Cl}: 1.33,4.11)$ and age of mothers $(\mathrm{AOR}=1.89$; $95 \%$ Cl: $1.09,3.27$ ) were positively associated with dietary diversity. Similarly, age of children ( $A O R=2.38 ; 95 \% \mathrm{Cl}: 1.56,3$. 65), household wealth status ( $A O R=1.84 ; 95 \% \mathrm{Cl}: 1.27,2.68)$, residence ( $\mathrm{AOR}=3.02 ; 95 \% \mathrm{Cl}: 1.41,6.48)$, sources of information (AOR $=1.72 ; 95 \%$ Cl:1.14, 2.59) and participation in child growth monitoring folow ups (AOR = 1.57; 95\% Cl: 1. $13,2.19)$ were significantly associated with meal frequency.

Conclusion: In this study, the proportion of children who received the minimum dietary diversity and meal frequency were low. Media exposure, age of children, postnatal care visits, and participation in child growth and monitoring followups were significantly associated with dietary diversity. Likewise, wealth status and residence had a significant association with meal frequency. Thus, encouraging all mothers to participate in child monthly growth monitoring programs, intensive media advertising and strengthening counseling of mothers, and postnatal care visit are highly recommended for achieving the recommended dietary practices.

Keywords: Children, Dietary diversity, Meal frequency, Ethiopia

\footnotetext{
* Correspondence: aysheshim121@gmail.com

${ }^{1}$ Department of Human Nutrition, Institute of Public Health, College of

Medicine and Health Sciences, University of Gondar, Gondar, Ethiopia

Full list of author information is available at the end of the article
} 


\section{Background}

Complementary feeding is the process of introducing other liquid and solid foods in addition to breastmilk when the energy demand of growing children does not maintain by breastmilk alone [1]. As infants and young children are found in dynamic growth and development, the World Health Organization (WHO) has recommended that solid, semisolid or soft foods should introduced at the age of six months [2-4], and that infants and young children should get the minimum meal frequency, dietary diversity, acceptable diet, and iron rich foods [5].

Globally, only $60 \%$ of infants start complementary feeding between the ages of 6 to 9 months. This indicates that millions of infants are given complementary foods either too early or too late [6]. For instance, in Africa less than one-third and around one-half (50\%) of the 6 to 23-months-old children meet the minimum criteria for dietary diversity and meal frequency, respectively [7]. In addition, only less than $20 \%$ of the children receive adequate complementary feeding. That is why the level of stunting in most African countries increases threefold during the two years of life [8].

Appropriate child feeding practice is vital in the first two years of life because malnutrition is common, especially in this age group. In addition, children become vulnerable to growth retardation, delayed mental development, micronutrient deficiencies, and common childhood illnesses and dealth [9, 10]. Moreover, inappropriate complementary feeding practices increase under five mortality by six-folds [11].

In Ethiopia, inappropriate complementary feeding practices were account for $57 \%$ of the deaths of underfive children, and $8.3 \%$ current workforce loss [12]. It has also contributed to $40 \%$ child stunting, $9 \%$ child wasting, and 25\% child underweight in Ethiopia [13].

Different studies have documented that dietary diversity and meal frequency are associated with sociodemographic characteristics. Accordingly, low levels of parental education, and age of mothers [14-16], maternal occupation [17], age and birth order of children [14, 15], household wealth status $[14,16]$, family size [14], and residence [15] were significantly associated with minimum dietary diversity practices . Furthermore, birth interval [18], satisfactory media exposure $[14,15]$, mother's involvement in decision making [15], maternal antenatal (ANC) and postnatal (PNC) care follow ups [18, 19] were significantly associated with practicing minimum meal frequency.

Nowadays, the Government of Ethiopia is giving especial attention to child health and nutrition. For instance, it has endorsed the National nutrition program, introduced free of charge antenatal care services, assigned two health extension workers to each 'Kebele' (The smallest administrative unit in Ethiopia), is used manual for complementary feeding practices, launched the monthly infant and child growth monitoring program and a continous media promotion on the importance of providing diversified and frequent diet to children. [20]. But according to the Ethiopian Mini Demography and Health Survey (EDHS) 2011 report, only $4.3 \%$ and $47.7 \%$ of children received the minimum dietary diversity and meal frequency, respectively [21].

As a matter of fact, is known about the dietary diversity and meal frequency practices in the northwestern part of Ethiopia, especially Dabat District. But, comprehensive data is needed for policy makers, governmental and nongovernmental organizations who are working on infant and young child health and nutrition. Therefore, it is important to investigate the practices of dietary diversity, meal frequency, and its associated factors among infant and young children.

\section{Methods}

\section{Study setting and design}

A community-based cross-sectional study was conducted from February 15 to March 10, 2016, at Dabat District, northwest Ethiopia. The district is located at $814 \mathrm{~km}$ away from Addis Ababa, the capital city of Ethiopia, and $75 \mathrm{~km}$ away from Zonal town, Gondar. The district has 6 health centers and 35 health posts. A total of 8875 under two years of children were living in the study area. The district has four urban and twenty-six rural kebeles.

\section{Sample size and sampling producer}

All infants and young children 6-23 months old living in Dabat District were eligible for the study. The sample size was calculated using the single proportion formula by considering the following assumptions; the proportion of $12.6 \%$ for minimum dietary diversity [15], a $95 \%$ confidence level, and a 3\% margin of error for dietary diversity. Finally, 1034 was adopted by considering, a $10 \%$ non-response rate and a design effect of 2 . A multistage stratified sampling followed by the simple random sampling technique was employed to select the study participants. Initially, kebeles were stratified into urban and rural. Of the total 30 kebeles, nine (one urban and eight rural) were selected by the lottery method. Lists and the total number of infants and young children in all kebeles of the district were obtained from health extension workers. Then, the total number of infants and young children included in the study were proportionally allocated. Finally, the simple random sampling technique was used to select participants. 


\section{Data collection tool and procedure}

A structured interviewer-administered questionnaire was used to collect data. The questionnaire was adopted from EDHS 2011, WHO standardized questionnaire for IYCF practices, and other similar studies with some modification to fit the local context. The questionnaire was prepared in English and translated to Amharic and finally translated back to English to maintain consistency. A pretest was done on $5 \%$ of the sample out of the study area. Two days training was given to data collectors and supervisors. A total of nine clinical nurse data collectors and three public health expert supervisors were recruited for the study. During the data collection period, a close supervision was done by the principal investigator and the supervisors, by overseeing how data collectors run the questions to the respondents and checking the collected data for completeness. Appropriate feedback was given before the next data collection period.

\section{Assessment of dietary diversity and meal frequency}

Determination of the dietary diversity score (DDS) of each child was started by asking the mother to list all food consumed by the child in the $24 \mathrm{~h}$ preceding the survey. Then, the reported food items were classified into seven food groupsas grains, roots and tubers, legumes and nuts, dairy products (milk, yogurt, cheese), flesh foods (meat, fish, poultry and liver/organ meats), eggs, vitamin-A-rich fruits and vegetables,other fruits and vegetables. Children getting four or more food groups were classified as meeting the minimum dietary diversity; otherwise, they were considered as getting low minimum dietary diversity [2].

Similarly, meal frequency of the child was determined by asking the mother how many times the child took solid, semi-solid, or soft foods in the $24 \mathrm{~h}$ preceding the survey. Accordingly, two or more times for breastfed infants 6 to 8.9 months of age, three or more times for breastfed children 9 to 23.9 months, and four times for non-breastfed children 6 to 23.9 months were considered as the children received the minimum meal frequency [2].

\section{Assessment of media exposure}

A woman aged 15 to 49 years and read a newspaper or magazine at least once a week or listened to the radioor watched television was considered as having a satisfactory media exposure.

Household wealth index was determined using Principal Component Analysis (PCA) by considering household assets, such as quantity of cereal products, house, livestock and agricultural land ownership. First, variables were coded between 0 and 1 . Then, they were entered and analyzed using PCA, and variables with a communality value of greater than 0.5 were used to produce factor scores. Finally, the factor scores were summed and ranked into tertiles as poor, medium, and rich.

\section{Data processing and analysis}

All of the returned copies of the questionnaire were manually checked for completeness and consistency of responses. Then, the collected data were entered into EPI-INFO version 7 and exported to SPSS version 20 for further analysis. The dietary diversity and meal frequency indicator was dichotomous variable classified into 0 and 1 , representing those who met and those who did not meet the minimum dietary and the minimum feeding practices, respectively. Descriptive statistics were summarized by using figures, tables, and texts. Both the bivariable and multivariable logistic regression analyses were used to identify variables associated with dietary diversity and meal frequency. Variables with less than 0.2 $p$-values in the bivariable analyses were fitted into the multivariable logistic regression analysis. Both Crude Odds Ratio (COR) and Adjusted Odds Ratio (AOR) with the corresponding 95\% Confidence Interval were calculated to show the strength of the association. Finally, in the multivariable analysis, variables with less than 0.05 $P$-values were considered as statistically significant.

\section{Results}

\section{Socio-demographic characteristics}

A total of 1034 infants and young children aged 6 to 23 months were enrolled along with their mothers. The mean age $( \pm$ SD) of the mothers was $29.06 \pm 6.58$ years. Almost all, 1033 (99.9\%), of the participants were Amhara by ethnicity and 996 (96.3\%) were Orthodox chiristians. Two-thirds, 685 (68.2\%), of the mothers were unable to read and write. About 947 (91.6\%) of the mothers were housewives (Table 1).

\section{Child, household, and community-related characteristics}

Of the total children, 527 (51\%) were male. The mean $( \pm \mathrm{SD})$ age of the children was $13.74 \pm 5.31$ months. Most, 1031 (97\%), of the children were breastfed at the time of data collection. The majority of the mothers, 971 (93.9\%), were involved in household decision making, and one-quarter, 269 (26.1\%), were found in the poor wealth status (Table 2).

\section{Child, and health care level related characteristics}

More than half, $(57.8 \%)$, of children were born at a health institution. Most, 872 (84.3\%), of the mothers' sources of information about IYCF practices were health professionals. This study also showed that two-thirds, 699 (67.6\%), of the mothers attended four and above ANC follow-ups and 393 (38\%) of the mothers had PNC visits. 
Table 1 Parental level characteristics of children aged 6-23 months, Dabat, Northwest Ethiopia, $2016(n=1034)$

\begin{tabular}{|c|c|c|}
\hline Variables & Frequency & Percentage \\
\hline \multicolumn{3}{|l|}{ Mother's age } \\
\hline $15-24$ & 22 & 2.1 \\
\hline $25-34$ & 525 & 50.8 \\
\hline $35-50$ & 487 & 47.1 \\
\hline \multicolumn{3}{|l|}{ Marital status } \\
\hline Married & 979 & 94.7 \\
\hline Separate & 19 & 1.8 \\
\hline Divorced & 17 & 1.6 \\
\hline Single & 16 & 1.5 \\
\hline Widowed & 3 & 0.3 \\
\hline \multicolumn{3}{|l|}{ Mother's education } \\
\hline Unable to read and write & 685 & 68.2 \\
\hline Primary education & 255 & 24.7 \\
\hline Secondary education & 55 & 5.3 \\
\hline Higher education & 39 & 3.8 \\
\hline \multicolumn{3}{|l|}{ Father's education } \\
\hline Unable to read and write & 503 & 48.8 \\
\hline Primary education & 413 & 40 \\
\hline Secondary education & 71 & 6.9 \\
\hline Higher education & 44 & 4.3 \\
\hline \multicolumn{3}{|l|}{ Mother's occupation } \\
\hline Housewife & 947 & 91.6 \\
\hline Government employee & 53 & 5.1 \\
\hline Merchant & 22 & 2.1 \\
\hline Student & 7 & 0.7 \\
\hline Daily laborer & 5 & 0.5 \\
\hline \multicolumn{3}{|l|}{ Father's occupation } \\
\hline Farmer & 814 & 79 \\
\hline Government employee & 73 & 7.1 \\
\hline Daily laborer & 66 & 6.4 \\
\hline Merchant & 52 & 5.0 \\
\hline Self employee & 26 & 2.5 \\
\hline
\end{tabular}

\section{Dietary diversity and meal frequency practices}

The proportion of children who received the recommended minimum dietary diversity and meal frequency was $17 \%$ (95\% CI: $14.9,19.4 \%)$ and $72.2 \%$ (95\% CI: 69.3, $75 \%)$, respectively. Grains, tubers, and roots were provided to the greatest number of children (84.6\%), and only a few (5.5\%), were given other fruits and vegetables (Fig. 1).

\section{Factors associated with dietary diversity and meal frequency}

The multivariate logistic regression output (Table 3) showed that postnatal care visits, participation in child
Table 2 Child, household and community characteristics of children aged 6-23 months, Dabat, Northwest Ethiopia, 2016 $(n=1034)$

\begin{tabular}{lll}
\hline variables & Frequency & Percentage \\
\hline Age of a child & & \\
6-11 month & 418 & 40.4 \\
12-17 month & 309 & 29.9 \\
$\begin{array}{l}\text { 18-23 month } \\
\text { Birth order }\end{array}$ & 307 & 29.7 \\
First & 215 & \\
Second to fifth & 675 & 60.8 \\
Above fifth & 144 & 13.9
\end{tabular}

Age when complementary feeding was started

$\begin{array}{lll}0-5 \text { months } & 92 & 8.9 \\ 6 \text { months } & 433 & 41.9 \\ 7-11 \text { months } & 395 & 38.2 \\ >=12 \text { months } & 114 & 11\end{array}$

Number of under five children

$\begin{array}{lll}\text { One } & 585 & 56.6 \\ \text { Two } & 442 & 42.7 \\ \text { Above three } & 7 & 0.7\end{array}$

Decision making at the household

Mothers participated

Mothers not participated

6.1

Household wealth status

Poor

26.1

Middle

40.1

Rich

33.8

Exposure to media

Unsatisfactory

80

Satisfactory

827

20

Residence

$\begin{array}{lll}\text { Rural } & 900 & 87\end{array}$

Urban

Home gardening

$\begin{array}{lll}\text { No } & 838 & 81.04 \\ \text { Yes } & 196 & 18.96\end{array}$

Purpose of home gardening $(n=196)$

\begin{tabular}{lll} 
For household consumption & 102 & 52.0 \\
$\begin{array}{l}\text { Both selling and for household } \\
\text { consumption }\end{array}$ & 90 & 45.9 \\
For selling & 4 & 2.1 \\
\hline
\end{tabular}

growth monitoring follow ups, media exposure, age of mothers and children were significantly associated with minimum dietary diversity. Whereas, residence, sources of information, family wealth status and age of children 


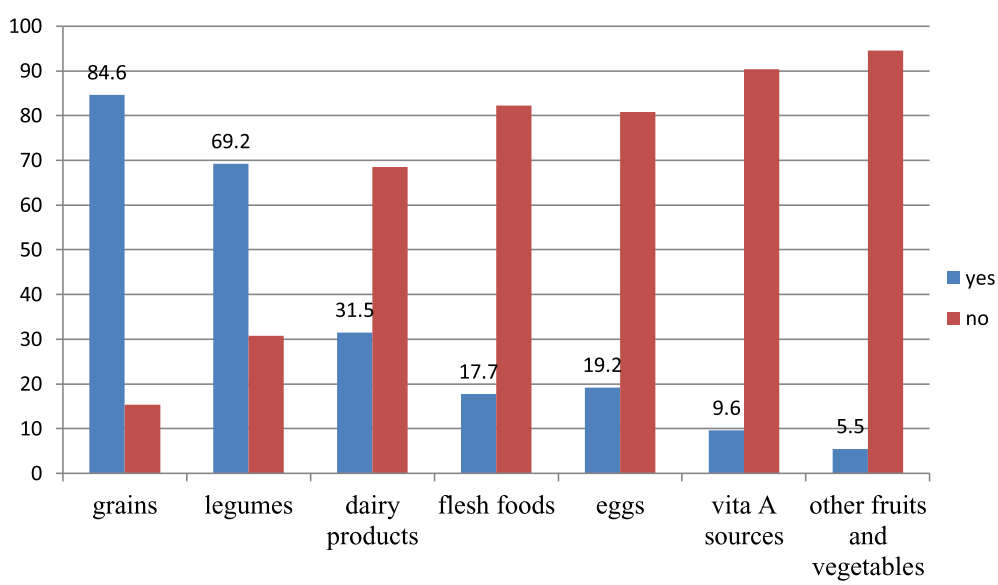

Fig. 1 Types of food groups practiced among 6-23 months children, in Dabat district, Northwest Ethiopia, 2016

were significantly associated with minimum meal frequency (Table 4).

Accordingly, mothers participating in growth monitoring follow-ups were 1.65 times $(\mathrm{AOR}=1.65 ; 95 \% \mathrm{CI}$ : $1.14,2.39)$ more likely to provide minimum dietary diversity compared to their counterparts. Similarly, higher odds of receiving adequate dietary diversity were observed among mothers who had postnatal care visits $(\mathrm{AOR}=1.95 ; 95 \% \mathrm{CI}: 1.34,2.88)$ and satisfactory media exposure $(\mathrm{AOR}=2.79$; 95\% CI: 1.74, 4.47).

Likewise, mothers who lived in the urban area were about 3 times more likely to provide the recommended minimum meal frequency compared to mothers who lived in the rural area (AOR $=3.02 ; 95 \% \mathrm{CI}: 1.41,6.48$ ). Mothers who obtained information from health professionals were 1.7 times more likely to provide minimum meal frequency compared to their counterparts $(\mathrm{AOR}=1.72$; 95\% CI: 1.14, 2.59). Moreover, children belonging to middle and rich wealth status families were 1.8 and 2.3 times (AOR $=1.84 ; 95 \% \mathrm{CI}: 1.27,2.68)$ and $(\mathrm{AOR}=2.40 ; 95 \% \mathrm{CI}: 1.568,3.69)$ more likely to receive the recommended minimum meal frequency, respectively, compared to poor wealth status families.

Finally, children in the $12-17$ and 18-23 month age groups were $2.4(\mathrm{AOR}=2.38 ; 95 \% \mathrm{CI}: 1.56,3.65)$ and 8 times $(\mathrm{AOR}=8.03 ; 95 \% \mathrm{CI}: 5.50,11.73)$ more likely to receive the recommended number of feeds, respectively, compared to children aged between 6 and 11 months.

\section{Discussion}

This community-based cross-sectional study identified that the proportion of children who received the minimum dietary diversity was 17\% (95\% CI: 14.9, 19.4\%). The finding is in line with the findings from Kenya (17.9\%) [22] and Ethiopia (17.8\%) [23]. But it is higher than the study reported in Zambia (12\%) [24]. The difference might on the result of the designs used. The five year longitudinal design in Zambia, for example, had the capacity of showing actual and summarized feeding practices of children. The current finding is also higher than the 2011EDHS report of $10.8 \%$ [14]. This difference might be due to the fact that the EDHS was nationwide done on a larger sample. In addition, the EDHS was conducted on culturally different population, which may inhibit child feeding practices. While the current study was conducted on almost culturally homogenous population with similar feeding practices.

However, our finding is lower than the national nutrition survey report of Afghanistan (27.6\%) [16], Pakistan (56.4\%) [25], Vietnam (71.6\%) [4], Zimbabwe (28\%) [26], and other similar studies in Ghana (34.8\%) [27]. The difference could be the low educational level of mothers compared to those of Afghanistan, Pakistan, Vietnam and Ghana. Uneducated mothers may not easily understand the consequences of undiversified diet and the nutritional requirements of infant and young children. According to previous studies, maternal education is one of the key determinant factors for practicing the minimum dietary diversity [14, 15, 19].

The proportion of children who the received minimum meal frequency was $72.2 \%$ (95\% CI: 69.3, 75\%). The finding is also higher compared with the demographic and health survey (DHS) reports of Afghanistan 52.1\% [16], Pakistan 56.4\% [25], Zimbabwe 59\% [26], Indonesia 58.2\% [28], Malawi 53.5\% [29], and Ghana $57.3 \%$ [27]. This difference might be due to the fact that most of the surveys in Asian countries used DHS data, secondary data analysis which contain large populations with ethnic, religious, cultural, belief, and traditional variations. Whereas, due to better food production and high purchasing power is a responsible factor for higher meal frequency practice than Zimbabwe, Malawi, and Ghana [30]. But the practice is lower compared to that Vietnam (85.6\%) [4], and the finding of similar studies in Kolkata (78\%) 
Table 3 Factors associated with minimum dietary diversity practices among 6-23 months of children, Dabat district, Northwest Ethiopia, 2016

\begin{tabular}{|c|c|c|c|c|}
\hline \multirow[t]{2}{*}{ Variables } & \multicolumn{2}{|c|}{ Minimum dietary diversity } & \multirow{2}{*}{$\begin{array}{l}\text { Crude Odds Ratio } \\
\text { with } 95 \% \mathrm{Cl}\end{array}$} & \multirow{2}{*}{$\begin{array}{l}\text { Ajdusted Odds Ratio } \\
\text { with } 95 \% \mathrm{Cl}\end{array}$} \\
\hline & Adequate & Inadequate & & \\
\hline & $\mathrm{N}(\%)$ & $N(\%)$ & & \\
\hline \multicolumn{5}{|l|}{ Mother's education } \\
\hline Unable to read and write & $92(13.4)$ & $593(86.6)$ & 1.00 & 1.00 \\
\hline Primary education & 50 (19.6) & $205(80.4)$ & $1.57(1.08,2.30)$ & $1.24(0.79,1.95)$ \\
\hline Secondary education & $16(29)$ & $39(71)$ & $2.64(1.40,4.93)$ & $1.30(0.60,0.80)$ \\
\hline Higher education & $18(46.2)$ & $21(53.8)$ & $5.53(2.84,10.76)$ & $1.59(0.66,3.80)$ \\
\hline \multicolumn{5}{|l|}{ Age of children } \\
\hline $6-11$ & $17(8.1)$ & $192(91.9)$ & 1.00 & 1.00 \\
\hline $12-17$ & $33(15.8)$ & $176(84.2)$ & $2.12(1.14,3.94)$ & $1.41(0.73,1.71)$ \\
\hline $18-23$ & $126(20.5)$ & $490(79.50)$ & $2.90(1.70,4.95)$ & $2.34(1.33,4.11)^{*}$ \\
\hline \multicolumn{5}{|l|}{ Birth order } \\
\hline First & $47(21.9)$ & $168(78.1)$ & 1.00 & 1.00 \\
\hline Second to fourth & $95(17.3)$ & $453(82.7)$ & $0.75(0.51,1.11)$ & $0.70(0.41,1.19)$ \\
\hline Above fourth & 34 (21.9) & $237(87.5)$ & $0.51(0.32,0.83)$ & $0.74(0.37,1.48)$ \\
\hline \multicolumn{5}{|l|}{ Media exposure } \\
\hline Unsatisfactory & $101(12.2)$ & $726(87.8)$ & 1.00 & 1.00 \\
\hline Satisfactory & $75(36.2)$ & $132(63.8)$ & $4.08(2.87,5.81)$ & $2.79(1.74,4.47)^{*}$ \\
\hline \multicolumn{5}{|l|}{ Household wealth status } \\
\hline Poor & $32(11.9)$ & $237(88.1)$ & 1.00 & 1.00 \\
\hline Middle & $65(15.7)$ & $350(84.3)$ & $1.37(0.87,2.17)$ & $1.53(0.94,2.47)$ \\
\hline Rich & $79(22.6)$ & $271(77.4)$ & $2.16(1.38,3.37)$ & $1.35(0.81,2.25)$ \\
\hline \multicolumn{5}{|l|}{ Residence } \\
\hline Rural & $130(14.4)$ & $770(85.6$ & 1.00 & 1.00 \\
\hline Urban & $46(34.3)$ & $88(65.7)$ & $3.10(2.07,4.63)$ & $1.14(0.62,1.20)$ \\
\hline \multicolumn{5}{|l|}{ Postnatal visit } \\
\hline No & $75(11.7)$ & $566(88.3))$ & 1.00 & 1.00 \\
\hline Yes & $101(25.7)$ & $292(74.3)$ & $2.61(1.88,3.63)$ & $1.95(1.34,2.88)^{*}$ \\
\hline \multicolumn{5}{|l|}{ Home gardening } \\
\hline No & $163(16.5)$ & $825(83.5)$ & 1.00 & 1.00 \\
\hline Yes & $13(28.3)$ & $33(71.7)$ & $1.99(1.03,3.87)$ & $1.88(0.91,3.92)$ \\
\hline \multicolumn{5}{|l|}{ Place of birth } \\
\hline Home & $114(64.8)$ & $62(35.2)$ & 1.00 & 1.00 \\
\hline Health institution & $484(56.4)$ & $374(43.6)$ & $0.70(0.50,0.98)$ & $0.93(0.63,1.37)$ \\
\hline \multicolumn{5}{|c|}{ participation in growth monitoring follow up } \\
\hline No & $78(13.7)$ & $493(86.3)$ & 1.00 & 1.00 \\
\hline Yes & $98(21.2)$ & $365(78.8)$ & $1.70(1.22,2.35)$ & $1.65(1.14,2.39)^{*}$ \\
\hline \multicolumn{5}{|l|}{ Currently breastfed } \\
\hline No & $10(32.3)$ & $21(67.7)$ & $2.40(1.11,5.19)$ & $1.02(0.24,4.38)$ \\
\hline Yes & $166(16.6)$ & $837(83.4)$ & 1.00 & 1.00 \\
\hline \multicolumn{5}{|l|}{ Age of mothers } \\
\hline $15-24$ & $36(14.6)$ & $210(85.4)$ & 1.00 & 1.00 \\
\hline $25-34$ & $107(20.4)$ & 418 (79.6) & $1.49(0.99,1.39)$ & $1.89(1.09,3.27)^{*}$ \\
\hline $35-50$ & $33(12.5)$ & $230(87.5)$ & $0.84(0.50,1.39)$ & $1.07(0.57,2.14)$ \\
\hline
\end{tabular}

*indicate significant at $p$ value less than 0.05 in multivariable logistic analysis 
Table 4 Factors associated with minimum meal frequency practices among 6-23 months of children, Dabat district, Northwest Ethiopia, 2016

\begin{tabular}{|c|c|c|c|c|}
\hline \multirow[b]{2}{*}{ Variable } & \multicolumn{2}{|c|}{ Minimum meal frequency } & \multirow[b]{2}{*}{$\begin{array}{l}\text { Crude Odds Ratio } \\
\text { with } 95 \% \mathrm{Cl}\end{array}$} & \multirow[b]{2}{*}{$\begin{array}{l}\text { Ajdusted Odds Ratio } \\
\text { with } 95 \% \mathrm{Cl}\end{array}$} \\
\hline & $\begin{array}{l}\text { Yes } \\
\text { N (\%) }\end{array}$ & $\begin{array}{l}\text { No } \\
\text { N (\%) }\end{array}$ & & \\
\hline \multicolumn{5}{|l|}{ Mother's education } \\
\hline Unable to read and write & $475(69.3)$ & $210(30.7)$ & 1.00 & 1.00 \\
\hline Primary education & $193(75.7)$ & $62(24.3)$ & $1.38(0.99,1.912)$ & $1.39(0.93,2.10)$ \\
\hline Secondary education & $42(76.4)$ & $13(23.6)$ & $1.43(0.75,2.72)$ & $1.01(0.43,2.38)$ \\
\hline Higher education & $37(94.9)$ & $2(5.1)$ & $8.18(1.99,34.25)$ & $2.22(0.37,13.14)$ \\
\hline \multicolumn{5}{|l|}{ Age of the child (months) } \\
\hline $6-11$ & $86(41.9)$ & $123(58.9)$ & 1.00 & 1.00 \\
\hline $12-17$ & $139(66.5)$ & $70(33.5)$ & $2.84(1.91,4.228)$ & $2.38(1.56,3.65)^{*}$ \\
\hline $18-23$ & $522(84.7)$ & $94(15.3)$ & $7.94(5.58,11.29)$ & $8.03(5.50,11.73)^{*}$ \\
\hline \multicolumn{5}{|l|}{ Media exposure } \\
\hline unsatisfactory & $571(69)$ & $256(31)$ & 1.00 & 1.00 \\
\hline Satisfactory & $176(85)$ & $31(15)$ & $2.55(1.69,3.83)$ & $1.31(0.77,2.21)$ \\
\hline \multicolumn{5}{|l|}{ Household wealth status } \\
\hline Poor & $169(62.8)$ & $100(37.2)$ & 1.00 & 1.00 \\
\hline Middle & $296(71.3)$ & $119(28.7)$ & $1.47(1.06,2.04)$ & $1.84(1.27,2.68)^{*}$ \\
\hline Rich & $282(80.6)$ & 68 (19.4) & $2.45(1.71,3.53)$ & $2.39(1.57,3.67)^{*}$ \\
\hline \multicolumn{5}{|l|}{ Residence } \\
\hline Rural & $625(69.4)$ & 275 (30.6) & 1.00 & 1.00 \\
\hline Urban & $122(91)$ & $12(9)$ & $4.47(2.43,8.23)$ & $3.02(1.41,6.48)^{*}$ \\
\hline \multicolumn{5}{|l|}{ Postnatal visit } \\
\hline No & $426(64.5)$ & $215(33.5)$ & 1.00 & 1.00 \\
\hline Yes & $321(81.7)$ & $72(18.3)$ & $2.25(1.66,3.05)$ & $1.81(1.26,2.60)^{*}$ \\
\hline \multicolumn{5}{|l|}{ Receiving information on IYCF } \\
\hline No & $96(59.3)$ & $66(40.7)$ & 1.00 & 1.00 \\
\hline Yes & $651(74.7)$ & $221(25.3)$ & $2.025(1.43,2.87)$ & $1.72(1.14,2.59)^{*}$ \\
\hline \multicolumn{5}{|c|}{ Participation in growth monitoring follow ups } \\
\hline No & $379(66.4)$ & $192(33.6)$ & 1.00 & 1.00 \\
\hline Yes & $368(79.5)$ & $95(20.5)$ & $1.96(1.48,2.61)$ & $1.57(1.12,2.19)^{*}$ \\
\hline \multicolumn{5}{|l|}{ Husband's education } \\
\hline Unable to read and write & $350(69.7)$ & $152(30.3)$ & 1.00 & 1.00 \\
\hline Primary education & $298(72)$ & $116(28)$ & $1.11(0.83,1.47)$ & $0.88(0.63,1.23)$ \\
\hline secondary education & $55(77.5)$ & $16(22.5)$ & $1.48(0.82,2.67)$ & $1.33(0.58,3.04)$ \\
\hline College diploma \&above & $41(93.2)$ & $3(6.8)$ & $5.94(1.81,19.46)$ & $3.27(0.37,28.75)$ \\
\hline \multicolumn{5}{|l|}{ Father's Occupation } \\
\hline farmer & $573(67)$ & $241(33)$ & $1.06(0.46,2.42)$ & $1.83(0.63,5.31)$ \\
\hline Government employee & $66(90.4)$ & $7(9.6)$ & $4.19(1.34,13.11)$ & $1.24(0.31,4.92)$ \\
\hline Daily laborer & $49(74.2)$ & $17(25.8)$ & $1.28(0.47,3.48)$ & $1.89(0.57,6.31)$ \\
\hline merchant & $41(78.8)$ & $11(21.2)$ & $1.66(0.57,4.81)$ & $1.15(0.37,3.52)$ \\
\hline Self employee & $18(69.2)$ & $8(30.8)$ & 1.00 & 1.00 \\
\hline
\end{tabular}

*indicate significant at $p$ value less than 0.05 in multivariable logistic analysis 
[31], Zimbabwe (91\%) [26],and Kenya (85.3\%) [22]. The difference could be due to lack awareness of mothers about how many times they should give solid, semisolid, and soft food to their children and lack of food stability. In addition, caregiver's level of encouragement during feeding may contribute to low prevalence [30].

Mothers involved in the monthly growth monitoring follow-ups were more likely to provide the recommended dietary diversity and meal frequency compared to their counterparts. A similar finding was reported from Southern Ethiopia [18]. This could be due to growth monitoring and promotions supported by individual counseling and community conversations which are likely to enhance the understanding of mothers about how to prepare and feed their children with diversified foods. In addition, the monthly growth monitoring program is supported by practical demonstrations on complementary food preparation.

Mothers with satisfactory media exposure were about 2.8 times more likely to practice adequate dietary diversity compared to mothers with unsatisfactory media exposure. This finding is in line with another finding in Ethiopia [14, 15]. Because media promotion enhances timely, adequate, safe,and proper feeding practices. Moreover, the Ethiopian Ministry of Health and its partners distribute radio and family health cards to the health development army, which is an important tool for improving dietary diversity practices of the community.

Postnatal care visit was significantly associated with infant and young child feeding practices. Accordingly, mothers who had postnatal care visits were more likely to provide the recommended dietary diversity and meal frequency compared to their counterparts. This finding is supported by the finding from Sri Lanka [19]. This could be due to the fact that nutritional advice and counseling by health workers might not only educate mothers but also avoids traditional beliefs that might inhibit child feeding practices.

In this study, mothers in the 25-34 years age group were about 2 times more likely to provide diversfied foods compared to mothers in the 15-24 years age group. This finding is supported by the 2011 EDHS report [14]. The possible explanation is that mothers in this age group had a better educational status (69.2\%), college diploma and above, and a high proportion,(59.4\%) and $(53.4 \%)$ had satisfactory media exposure and PNC service utilization, respectively.

Likewise, the likelihood of receiving the minimum dietary diversity among children aged 18-23 months was 2.3 times more compared to children aged 611 months. This finding is in line with that of EDHS 2011 [14], Dangila [15] and Mekelle [23]. This could be due to the fact that as the age of children increases, the probability of receiving diversified foods increases and the misconceptions of mothers that younger infants and children could not be able to digest food like meat and egg decreases [28]. On tip of that, advances in the age of the children may encourage mothers to initiate complementary feeding as observed in this investigation.

Wealth status of the family was one of the determinant factors for meal frequency. Accordingly, children belonging to middle and rich wealth status families were about 2 times more likely to receive the minimum meal frequency as compared to children belonging to poor wealth status families. This result is similar to that of study conducted in Dangila town, Ethiopia [15] and south Asiatic countries like India, Sir lanka, and Nepal [19]. This may due to the fact that middle and rich wealth status families are more likely to be food secure and have the ability to purchase different consumables goods for their families.

Mothers lived in the urban area were more likely to provide the recommended minimum meal frequency as compared to mothers who lived in the rural area. The possible explanation is that mothers who live in the urban area have good awareness on feeding practices of infants and young children, while urban mothers have access to media which promote the importance of complementary feeding practices as compare to rural mothers. In addition to these access to markets for consumption goods, food and to places of incomegenerating employment is essential in urban area.

Mothers who obtained information from health professionals were more likely to provide the recommended meal frequency compared to their counterparts. This finding is similar to that of a study conducted in India [32]. This is because health professionals can transmit the appropriate messages on child feeding practices during the critical contact time.

Children in the age group of 12-17 months and 1823 months were about 2 and 8 times more likely to receive the recommended meal frequency as compared to children in the age group of 6-11 months. This finding is supported by that of another study conducted in Ethiopia [14]. This is probably because infants $6-8$ months old are mostly breastfed, so the need for a frequent feeding of extra solid food is not perceived as important or a priority by mothers and caretakers for feeding infants of this age. In addition, older children have the chance of eating family diet, which increases feeding frequency.

The study attempted to show child feeding practices in a well-defined population representing rural northwest Ethiopia. However, some of the limitations of this study should be taken into consideration. First, the study did not consider the quantity of food consumed by the 
children and a single 24-h recall did not indicate the usual dietary habit of the children. Second, even though adequate training was given to field assistants (data collectors and supervisors) and mothers were clearly informed about the objectives of the study, there might still be a social desirability and recal bias in reporting the type of food given to children.

\section{Conclusion}

This study revealed that only a few children received dietary diversity and meal frequency as measured by the WHO indicators. Postnatal care visits, age of child, and growth monitoring participation of mothers affect both minimum dietary diversity and meal frequency practices. Lack of media exposure and younger age of mothers affect minimum dietary diversity, while rich wealth status of household, residence, and information from health professional were associated with meal frequency. Hence, encouraging all mothers to participate in monthly growth monitoring, intensive media advertising and strengthening counseling of mothers attending PNC are proposed for achieving the recommended infant and young child infant and young child feeding practices.

\section{Abbreviations}

ANC: Antenatal Care; AOR: Adjusted Odd Ratio; CF: Complementary Feeding; $\mathrm{Cl}$ : Confidence Interval; COR: Crude Odd Ratio; EDHS: Ethiopian Demographic and Health Survey; FMOH: Federal Ministry of Health; IYCF: Infant and Young Child Feeding; MDD: Minimum Dietary Diversity; MMF: Minimum Meal Frequency; PNC: Postnatal Care; UNICEF: United Nations Children Fund; USAID: United State Agency for International Development; WABA: World Alliance for Breastfeeding Action; WHO: World Health Organization

\section{Acknowledgements}

The authors would like to thank all respondents for their willingness to participate in the study. They are also grateful to North Gondar Zonal Health Department, Dabat District Health Officefor their cooperation and the University of Gondar for material support.

\section{Funding}

No was obtained for this study.

\section{Availability of data and materials}

Data will be available upon request from the corresponding authors.

\section{Authors' contributions}

AK conceived the study, developed the tool, coordinated the data collection activity, and carried out the statistical analysis and writing manuscript.. BM participated in the design of the study, tool development, and drafting the manuscript. ZA participated in the design of the study and tool development, performed statistical analysis, and drafted the manuscript. BA also participated in the design of the study and tool development, performed statistical analysis, and drafted the manuscript. All authors read and approved the final manuscript.

\section{Ethics approval and consent to participate}

Ethical clearance was obtained from the Institutional Ethical Review Board of the University of Gondar. Supportive letters were obtained from the Zonal Health Department and Dabat District Health Office. Informed oral consent was obtained from each mother responding to the questions after clearly informing the purpose, benefits, confidentiality of the information, and the voluntary nature of the participation in the study. Names and other personal identifiers were not recorded to maintain confidentiality.
Consent for publication

Not applicable.

\section{Competing interests}

The authors declare that they have no competing of interests.

\section{Publisher's Note}

Springer Nature remains neutral with regard to jurisdictional claims in published maps and institutional affiliations.

\section{Author details}

${ }^{1}$ Department of Human Nutrition, Institute of Public Health, College of Medicine and Health Sciences, University of Gondar, Gondar, Ethiopia. ${ }^{2}$ Department of Epidemiology and Biostatistics, Institute of Public Health, College of Medicine and Health Sciences, University of Gondar, Gondar, Ethiopia.

Received: 1 May 2017 Accepted: 28 July 2017

Published online: 15 August 2017

\section{References}

1. World Health Organization. Strengthening action to improve feeding of infants and young children 6-23 months of age in nutrition and child health programmes: report of proceedings, Geneva, 6-9 October 2008. 2008

2. World Health Organization. Indicators for assessing infant and young child feeding practices: part 1: definitions: conclusions of a consensus meeting held 6-8 November 2007 in Washington DC, USA. 2008.

3. Ministry of Health Federal Democratic Republic of Ethiopia. Infant \& Young Child Feeding Quick Reference Book (0-24 months). 2010.

4. Nguyen PH, Kim SS, Keithly SC, Hajeebhoy N, Tran LM, Ruel MT, et al. Incorporating elements of social franchising in government health services improves the quality of infant and young child feeding counselling services at commune health centres in Vietnam. Health Policy Plan. 2014;29(8):1008-20.

5. World Health Organization. Indicators for assessing infant and young child feeding practices: part 3: country profile. Geneva: WHO; 2010.

6. World Health Organization. Indicators for assessing infant and young child feeding practices, Part 3: country profiles. Indicators for assessing infant and young child feeding practices, Part 3: country profiles. 2010

7. Lutter CK. Growth and complementary feeding in the Americas. Nutrition, metabolism, and cardiovascular diseases : NMCD. 2012;22(10):806-12. Epub 2012/08/25

8. Africa union. African regional nutrition strategy. Addis Ababa, Ethiopia: African Union; 2015.

9. Ministry of Health, Federal Democratic Republic of Ethiopia. Infant \& Young Child Feeding Quick Reference Book (0-24 months)2010.

10. Jäpölä J-P. Legal view of controlling development cooperation appropriations in Finland. 2015

11. UNICEF. Programming Guide,Infant and Young Child Feeding. 2012

12. Federal ministry of Health. National strategy for child survival in Ethiopia. Addis Ababa, Ethiopia,2005.

13. Ethiopia Demographic and health survey. Ethiopia Mini Demographic and Health Survey. Central Statistical Agency,Addis Ababa, Ethiopia, 2014.

14. Aemro M, Mesele M, Birhanu Z, Atenafu A. Dietary diversity and meal frequency practices among infant and young children aged 6-23 months in Ethiopia: a secondary analysis of Ethiopian demographic and health survey 2011. Journal of nutrition and metabolism. 2013;2013:782931.

15. Beyene M, Worku AG, Wassie MM. Dietary diversity, meal frequency and associated factors among infant and young children in Northwest Ethiopia: a cross-sectional study. BMC Public Health. 2015;15(1):1007.

16. Afghanistan Ministry of Public Health. National Nutrition Survey Afghanistan. 2013.

17. Victor R, Baines SK, Agho KE, Dibley MJ. Factors associated with inappropriate complementary feeding practices among children aged 6-23 months in Tanzania. Maternal \& child nutrition. 2014;10(4):545-61.

18. Tessema M, Belachew T, Ersino G. Feeding patterns and stunting during early childhood in rural communities of Sidama, South Ethiopia. Pan African Medical Journal. 2013;14(1):75.

19. Senarath U, Dibley MJ. Complementary feeding practices in South Asia: analyses of recent national survey data by the South Asia infant feeding research network. Maternal \& child nutrition. 2012;8(s1):5-10. 
20. Federal ministry of Health. National strategy for child survival in Ethiopia. Addis Ababa, Ethiopia: Federal ministry of Health; 2005.

21. Ethiopia Demographic and Health survey. Ethiopia Demographic and Health Survey report. Central Statistical Agency,Addis Ababa, Ethiopia,ICF International,Calverton, Maryland, USA, 2011.

22. Gichana MB. Nutritional knowledge of mothers and nutritional status of their children 6-59 months under Malezi bora Programme in Kawangware sub location. Dagoretti, Nairobi County: University of Nairobi; 2013.

23. Mekbib E, Shumey A, Ferede S, Haile F. Magnitude and factors associated with appropriate complementary feeding among mothers having children 6-23 months-of-age in northern Ethiopia; a community-based cross-sectional study. J Food Nutr Sci. 2014;2(2):36

24. Mallard SR, Houghton LA, Filteau S, Mullen A, Nieuwelink J, Chisenga M, et al, Dietary diversity at 6 months of age is associated with subsequent growth and mediates the effect of maternal education on infant growth in urban Zambia. J Nutr. 2014;144(11):1818-25.

25. Aga Khan University. Pakistan National Nutrition Survey 2011. Planning commission, Planning and Development Division,Government of Pakistan, 2013.

26. Zimbabwe National Statistics Agency. Mulitiple indicator cluster survey 2014. Harare, Zimbabwe: 2014, 2014.

27. Saaka M, Larbi A, Mutaru S, Hoeschle-Zeledon I. Magnitude and factors associated with appropriate complementary feeding among children 6-23 months in northern Ghana. BMC Nutrition. 2016;2(1):2.

28. Indonesia International Institute for Life Sciences. Food and dietary diversity in the context of food and nutrition security in Indonesia. 2104

29. Demographic Malawi. Health survey 2010 Zomba. Malawi: National Statistical Office of Malawi, ORC Macro. 2011

30. Issaka Al. Complementary feeding practices in West Africa: statistics, epidemiology and policy implications. 2015.

31. Dasgupta A, Harichandrakumar KT, Habeebullah S. Pregnancy outcome among obese Indians - a prospective cohort study in a tertiary Care Centre in South India. International Journal of Scientific Study. 2014;2(2):13-8.

32. Malhotra N. Inadequate feeding of infant and young children in India: lack of nutritional information or food affordability? Public Health Nutr. 2013; 16(10):1723-31.

\section{Submit your next manuscript to BioMed Central and we will help you at every step:}

- We accept pre-submission inquiries

- Our selector tool helps you to find the most relevant journal

- We provide round the clock customer support

- Convenient online submission

- Thorough peer review

- Inclusion in PubMed and all major indexing services

- Maximum visibility for your research

Submit your manuscript at www.biomedcentral.com/submit 